\title{
Too big to be noticed: Cryptic invasion of Asian camel crickets in North American houses
}

Despite the rapid expansion of the built environment, we know little about the biology of species living in human-constructed habitats. Camel crickets (Rhaphidophoridae) are commonly observed in North American houses and include a range of native taxa as well as the Asian Diestrammena asynamora (Adelung), a species occasionally reported from houses though considered to be established only in greenhouses. We launched a continental-scale citizen science campaign to better understand the relative distributions and frequency of native and nonnative camel crickets in human homes across North America. Participants contributed survey data about the presence or absence of camel crickets in homes, as well as photographs and specimens of camel crickets allowing us to identify the major genera and/or species in and around houses. Together, these data offer insight into the geographical distribution of camel crickets as a presence in homes, as well as the relative frequency and distribution of native and nonnative camel crickets encountered in houses. In so doing, we show that the exotic Diestrammena asynamora not only has become a common presence in eastern houses, but is found in these environments far more frequently than native camel crickets. Supplemental pitfall trapping along transects in 10 urban yards in Raleigh, NC, revealed that $D$. asynamora can be extremely abundant locally around some homes, with as many as 52 individuals collected from pitfalls in a single yard over two days of sampling. The number of $D$. asynamora individuals present in a trap was negatively correlated with the trap's distance from a house, suggesting that these insects may be preferentially associated with houses but also are present outside. In addition, we report the establishment in the northeastern United States of a second exotic species, putatively Diestrammena japanica Blatchley, which was previously undocumented in the literature. Our results offer new insight 
into the relative frequency and distribution of camel crickets living in human homes, and emphasize the importance of the built environment as habitat for two little-known invading species of Orthoptera. 
1 Mary Jane Epps, ${ }^{*}$ Holly L. Menninger, ${ }^{*}$ Nathan LaSala, ${ }^{\dagger}$ Robert R. Dunn*

2 * Department of Biological Sciences, North Carolina State University, Raleigh, NC 27695

$3{ }^{\dagger}$ Enloe High School, Raleigh, NC 27610

4 Corresponding author information:

5 Mary Jane Epps

6127 David Clark Labs

7 NCSU Department of Biological Sciences,

8 Raleigh, NC 27695

9 mjepps@ncsu.edu 
INTRODUCTION

11 In the United States, $90 \%$ of the human population is predicted to live in urban environments by

122050 (U.N. 2012). At this time a large geographic area will be urban, peri-urban and suburban

13 (Nowak and Walton 2005), an area greater than that covered by many of North America's

14 primary vegetation types (Stein, Kutner, and Adams 2000). Although the species living in built

15 environments are among the organisms we see most often, they are not necessarily well-

16 documented. We suspect this is particularly true of species that are neither valued aesthetically as

17 are birds and butterflies, nor are important economic pests (such as bed bugs and roaches). Camel

18 crickets (Orthoptera: Rhaphidophoridae) are among the largest of the many insects that live in

19 modern-day houses, and have an especially longstanding history of contact with humans in our

20 homes. These insects have long been noted in basements and cellars, and one remarkable

21 example of cave art from Paleolithic France depicts the cave-dwelling camel cricket Trogophilus

22 sp. (hopard 1928). The relationship between camel crickets and humans is clearly ancient;

23 however, the biology of these insects as residents of our homes is known primarily from a

24 smattering of specimen records in museums rather than from formal study.

25 Camel crickets comprise a moderately diverse family of Orthoptera, represented by ca. 150

26 species (23 genera) across North America (Arnett 2000). Of these, several species in the large

27 genus Ceuthophilus Scudder (e.g., C. brevipes Scudder, C. pallescens Bruner, C. agassizii

28 (Scudder), C. latens Scudder, C. maculatus (Harris), and others) have been reported as common

29 or occasional inhabitants of North American homes, particularly in cellars and basements

30 (Blatchley 1920; Vickery and Kevan 1983). Outside of these habitats, most species of

31 Ceuthophilus (including those occurring in our houses) are found under rocks, logs, or surface

32 debris in forested areas, although a few are known from grassland ecosystems (Vickery and

33 Kevan 1983). Other Ceuthophilus (e.g., C. carlsbadensis Caudell, C. longipes Caudell, C. 
34 secretus Scudder, and others) are common residents of caves, where the droppings and carcasses

35 of these crickets are a major source of energy for other organisms. For this reason camel crickets

36 are considered keystone species in many cave ecosystems (Lavoie, Helf, and Poulson 2007;

37 Taylor, Krejca, and Denight 2005). Although cellars and basements share features with caves

38 (e.g., both tend to be damp, dark, and low in nutrients), most camel crickets found in our houses

39 appear to be distinct from species typically collected in caves (Vickery and Kevan 1983).

40 However, in at least one case (a camel cricket endemic to Tuscany, Italy, Dolichopoda

41 schiavazzii Capra), populations of an otherwise cave-inhabiting species are also known from

42 cellars and other subterranean environments of human origin (Allegrucci, Minasi, and Sbordoni

43 1997).

44 In addition to a rich diversity of native camel cricket species, non-native camel crickets have also

45 become established in North America. The 'greenhouse camel cricket,' Diestrammena

46 asynamora (Adelung) is a species native either to Japan or the Sichuan region of China (Rehn

47 1944). This species was first recorded in North America in 1898 from a greenhouse in Minnesota

48 (Rehn 1944), and subsequently has been noted in a number of locations across the eastern and

49 central United States and Canada. D. asynamora has also been found throughout much of Europe

50 (Rehn 1944). Many authors have considered this species to be associated primarily with

51 greenhouses (e.g. Bue and Munro 1939, Rehn 1944, Vickery and Kevan 1983), although a few

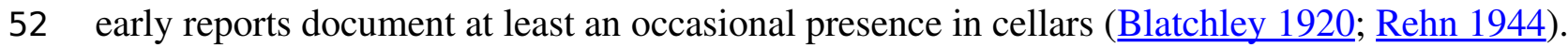

53 However, little discussion has been made of this species and its status since Rehn's 1944

54 publication. Modern reports of D. asynamora show that it is present in some basements, though it

55 is uncertain whether the sightings of this introduced cricket represent isolated cases of localized

56 abundance or a more extensive invasion. Recent anecdotal reports (www.bugguide.net) also 
57 suggest the establishment of a second Asian species, D. japanica Blatchley (syn. D. japonica

58 Karny, D. naganoensis Mori), around New York City, NY. Because camel crickets include both

59 introduced species and geographically and locally rare species, it is possible that basements and

60 cellars might be important habitats for the spread of introduced camel crickets and/or the

61 persistence of native camel cricket species.

62 One challenge with studying the biology of species living in homes is that privacy concerns make

63 these areas difficult to sample. However, citizen science may offer an ideal approach for studying

64 home biodiversity; volunteers can participate in scientific research by self-surveying their own

65 homes. Although obtaining accurate identifications of organisms from public survey data can be

66 challenging, many of the characters that distinguish camel crickets at the generic and/or species

67 level (e.g., coloration, tibial armature) may be visible in photographs. For this reason,

68 photographic documentation is an invaluable addition to public survey data, and provides an easy

69 way to confirm the presence and distribution of camel crickets in our homes.

70 In this study, we use citizen-contributed data to offer new insight into the distribution and

71 composition of camel crickets taking shelter in human homes. Initially, in order to understand

72 how common camel crickets are in houses, we surveyed citizens across the United States about

73 the presence of camel crickets living in and around their homes. We conducted this survey in two

74 ways: 1) we asked visitors to our website to report the presence/absence of camel crickets (as

75 well as other natural history observations in and around their home) via an open survey and 2) we

76 directly administered a closed survey that included a question about camel crickets to volunteers

77 wishing to participate in an unrelated citizen science project (about microbial diversity in the

78 home). We then solicited photographs and specimens of camel crickets from citizen scientists to

79 evaluate the occurrence and geographical distribution of native versus nonnative camel cricket 
80

81

82 METHODS

83 We used two types of citizen science surveys to characterize the geographic distribution and

84 composition of camel crickets in houses across the United States. First, as part of a broader study

85 about the ecology of human homes, we used an open web survey to poll people across the United

86 States about the organisms they find in their homes; this survey included questions about the

87 presence/absence of camel crickets in or around their homes and their geographic location

88 (Appendix A). We recruited participants to the survey through our website (yourwildlife.org),

89 social media and email campaigns, and the survey remained open to public responses from

90 December 2011 through July 2013. This initial survey had the potential to be biased toward

91 individuals who had camel crickets in their homes, as people may be more likely to report a

92 presence than absence (Bonney et al. 2009). As a result, we conducted a second survey by polling

93 a geographically stratified but naïve population of homeowners. We directly administered a

94 closed survey to 7058 households wishing to enroll in the Wild Life of Our Homes project

95 (WLOH, a separate study mapping the indoor microbial biodiversity of homes;

96 homes.yourwildlife.org) over the period October 2012 - April 2013. Volunteers, representing all

9750 states and the District of Columbia, were required to complete the brief survey (containing a

98 question about the presence/absence of camel crickets in the home, Appendix A) in order to

99 receive a home microbe sampling kit. Thus, participation was not a function of initial interest in

100 camel crickets, but in this other citizen science project, therefore reducing sampling bias.

101 The results of both surveys were used to map the presence of camel crickets in North American

102 homes. Maps were created using ArcGIS software (ESRI 2006) and R (http://www.r- 
103 project.org/). Only data from the second, WLOH participant survey were used to estimate the

104 prevalence of the crickets.

105 In order to understand the relative distribution of native versus nonnative camel crickets we next 106 solicited photographs and/or specimens of camel crickets from citizen volunteers who reported

107 these insects in their homes. These volunteers included a subset of participants from the surveys

108 described above, as well as additional individuals responding to an appeal for participation on the

109 Camel Cricket Census website (http://crickets.yourwildlife.org/). Photographs and specimens

110 were identified to genus based on tibial armature and other relevant characters described in

111 Vickery and Kevan (1983). Where possible, photographs and specimens of the nonnative

112 Diestrammena were further identified to species using characters such as the number of tibial

113 spines, tibial spur length, and color pattern as described in Sugimoto and Ichikawa (2003),

114 Vickery and Kevan (1983), and following consultation with experts.

115 Finally, to understand whether the Asian camel cricket D. asynamora is living only in houses or

116 also present in yard habitats, we sampled camel crickets in a subset of urban yards at increasing

117 distances from homes known to contain camel crickets. In July of 2013, 10 participating

118 households were recruited from central Raleigh, NC, and pitfall traps placed in the yard of each.

119 Study yards were located within a 1.5 mile radius of North Carolina State University's central

120 campus, and were typically a mix of sun and shade habitat with occasional scattered trees and

121 primarily grass as groundcover. We constructed pitfall traps using plastic cups ( $7 \mathrm{~cm}$ across by 10

$122 \mathrm{~cm}$ deep) and placed three traps per yard at distances of $1 \mathrm{~m}, 4 \mathrm{~m}$, and $8 \mathrm{~m}$ from each house along

123 a haphazardly placed transect. Traps were baited with a 1:1 dilution of molasses and water as per

124 the methods of Hubbell (1936). We placed inverted plastic bowls elevated approximately $3 \mathrm{~cm}$

125 over the mouth of each trap to protect traps from rain and to encourage camel cricket visitation by 
126 offering cover. Contents of traps were collected daily and traps were left in place for two days. In

127 some yards small mammals would disturb the traps, in which case we replaced the molasses bait

128 with soapy water in all traps on a transect to be less attractive to mammalian pests. We sorted the

129 contents of each trap in the laboratory and identified all camel crickets to species with the aid of a

130 dissecting microscope. We then used analysis of covariance (ANCOVA) to test for a relationship

131 between the number of $D$. asynamora individuals in a trap and its distance from a house. Yards in

132 which no camel crickets were recovered at any of the three traps were excluded from analysis.

133 Statistical analysis was performed in JMP v. 10.0 (SAS Institute, Cary, NC).

134 RESULTS

135 Individuals from 549 homes responded to our initial open survey question about the presence or

136 absence of camel crickets in or around their houses, offering positive reports of camel crickets for

137244 homes across the country. An additional 1,719 households responded to the unbiased (with

138 respect to camel cricket presence) WLOH participant questionnaire. Over both surveys,

139 participants from 669 houses reported having observed camel crickets in their homes, including

$14024.4 \%$ of households responding to the unbiased WLOH study (Fig. 1). Together, these surveys

141 allowed us to evaluate the potential distribution of camel crickets associated with human houses

142 across the United States. We use the word "detection" to acknowledge that reports of absence in

143 survey data may reflect failures to detect camel crickets, just as presences may represent failures

144 at identification. For example, a large spider might bear a vague resemblance to a camel cricket

145 for a participant wary of arthropods. Participants from 39 states and the District of Columbia

146 reported observing camel crickets in or around their homes (Fig. 2). The proportion of detections

147 of camel crickets in homes was significantly higher in the eastern United States (28\% of reports

148 were positive from states east of Colorado) compared to western states (7\% positive reports; two-

149 tailed $P<0.0001$ from Fisher's exact test). Based on the proportion of photographs showing 
150

insects incorrectly identified as camel crickets by citizen scientists who responded to our call for

151 photographs (see below), we estimated a $4.6 \%$ error rate associated with affirmative reports of

152 camel crickets from all survey data, although this error rate may vary geographically. From

153 Colorado westward only five photographs were submitted, of which 40\% (2 of 5) were identified

154 incorrectly as Rhaphidophoridae. The most common taxa mistaken for camel crickets were field

155 crickets (Gryllidae) or other Orthoptera.

156

157 Citizen scientists from 163 households submitted identifiable photographs $(\mathrm{N}=151)$ and/or

158 specimens $(\mathrm{N}=12)$ of camel crickets from their houses. Submissions spanned 23 states and the

159 District of Columbia, as well as one Canadian province with an overrepresentation of

160 submissions (37\%) from North Carolina. Out of all identifiable camel cricket submissions, $88 \%$

161 of houses submitted evidence of the Asian genus Diestrammena. Only $12 \%$ of houses reported

162 members of the native Ceuthophilus (Table 1, Fig. 3). In three cases, evidence of both native and

163 nonnative genera were contributed from the same home. Of the 143 submissions recognizable as

164 Diestrammena, 108 were of sufficient quality to allow identification to species. Of these, $94 \%$ of

165 entries were D. asynamora (Fig. 4a), while the remainder (seven entries) were identified as

166 putative $D$. japanica (Fig. 4b). Records of $D$. japanica were submitted exclusively from the

167 northeastern United States in Massachusetts, Pennsylvania, and New Jersey (Fig. 5).

168 We recovered 158 camel crickets from pitfall traps in urban yards in Raleigh, NC. Prior to our

169 investigation, eight of the 10 households participating in our trapping study reported previously

170 having seen camel crickets in their home. Camel crickets were found in seven of the yards

171 sampled, and were absent in both of the yards for which camel crickets were not reported in the

172 house. For houses initially reporting camel crickets as present, an average of 20 individual camel

173 crickets were recovered per yard over the two-day sampling period $(95 \%$ C.I. $=5-34$, range $=0$ - 
174 52). All recovered specimens of Rhaphidophoridae were identified as the Asian species $D$.

175 asynamora. The number of $D$. asynamora individuals recovered in traps was negatively

176 correlated with a trap's distance from a house $\left(R^{2}=0.66, P=0.004\right.$ from ANCOVA after $\ln$ -

177 transformation of the number of cricket individuals and after accounting for individual yard, as

178 would reflect variation in local abundances of camel crickets; Fig. 6). In fact, for every yard with

179 successful trapping, more crickets were consistently recovered at traps $1 \mathrm{~m}$ from the house than

180 were recovered from the two more distant traps combined. However, in $57 \%$ of these yards at

181 least one D. asynamora individual was recovered from the trap placed farthest from the house (8 $182 \mathrm{~m})$.

183 DISCUSSION

184 Although camel crickets have long been a common presence in our homes, little is known about

185 the identity, occupancy and geography of these animals in homes. Using data contributed by

186 citizen scientists, we found that camel crickets are common in houses across much of the

187 continental United States (Fig. 2), and present in as many as a quarter of homes surveyed as part

188 of another citizen science project. Based on our survey results, camel crickets appear to be

189 geographically widespread in homes particularly across the eastern half of the United States, and

190 to a lesser extent in the southwest and west coast (Fig. 1). Camel crickets were not reported in

191 homes throughout much of the mountain west, although responses from this region were sparse

192 relative to more populated parts of the country (Fig. 1, Fig. 2). Hence, there may be large areas in

193 the west where camel crickets are more common than our data indicate. However, the public can

194 still contribute data to this project, such that we hope to add data for the western U.S. in the

195 coming months or years (crickets.yourwildlife.org). Camel crickets appear to be most prevalent

PeerJ reviewing PDF | (v2014:05:2109:1:0:ACCEPTED 21 Jul 2014) 
196 in houses in the southeastern United States, with nearly 50\% of households surveyed in Virginia,

197 North Carolina, Missouri, Mississippi, Maryland, and Tennessee reporting the presence of camel 198 crickets in their homes (Fig. 1).

199 Although this survey was potentially biased geographically, it was not biased as a function of the 200 presence or absence of camel crickets. If the abundance of camel crickets (of any species) in and 201 around the average home where they are present is comparable to the abundance of these insects 202 recovered in our pitfall traps around homes in Raleigh, North Carolina, there could be as many as 203 seven hundred million camel crickets in and around homes across the eastern United States alone 204 (calculated based on the number of housing units reported in the 2011 U.S. Census for midwest, 205 northeast and south U.S. census regions for which our survey responses were generally high; see 206 Fig. 2; U.S. Census Bureau 2012). If correct, this would amount to more camel crickets than 207 humans. Although clearly a very rough estimate (e.g., we do not account for other factors such as 208 regional geographic variation in abundance), this figure nonetheless offers a rough estimate of the 209 large populations of camel crickets that may have become established in and around built 210 environments. The size of these populations is all the more remarkable when we consider that

211 most of these camel crickets belong to an introduced species previously not known to be

212 especially common; in contrast, native species appear to be comparatively rare in these

213 environments.

214 Citizen scientists' submissions of photographs and specimens of camel crickets found in homes

215 reveal that the Asian camel cricket D. asynamora has become a successful and widespread

216 invader throughout the eastern United States (Fig. 3). Across much of this region this species

217 appears to be a much more common occupant of human homes compared to native Ceuthophilus 218 spp. (Table 1). For example, in North Carolina, the state for which we have the richest data, 
219

220

221

222

223

224

225

226

227

228

229

230

231

232

233

234

235

236

237

238

239

240 living and dead plant matter and dead insects. The habits and dietary preferences of our native

241 Ceuthophilus spp. are only somewhat better known than those of D. asynamora. Species of

Diestrammena (representing D. asynamora in all identifiable entries) was present in $92 \%$ of

houses with camel cricket samples submitted (Table 1). Our pitfall trapping in urban yards

reveals that this species also can be extremely abundant, with more than 50 individuals found

over two days of sampling in a single yard in Raleigh, North Carolina.

Although D. asynamora is clearly widespread and abundant in the eastern United States, the

extent of this species' range outside of the eastern United States is unclear. Rehn (1944) describes

reports of the species in greenhouses and cellars from Maine south to Tennessee, and as far west

as Colorado. While his reports derive from a small number of museum specimens combined with

scattered anecdotes, they already cover a relatively large geographic area. Our study includes

reports of the species only as far west as Kansas, though extending further south into Georgia and

South Carolina. Other reports suggest an even larger distribution, but lack of specimen data

makes comparison to our results difficult (Vickery and Kevan 1983). According to most

accounts, established populations of this species were thought to be present in greenhouses only

(Blatchley 1920, Vickery and Kevan 1967, Vickery and Kevan 1983). Hence, D. asynamora

likely may have increased in abundance since 1944, particularly in houses; however, the species

does not necessarily appear to have expanded its geographic distribution.

Despite the abundance of D. asynamora in and around the home, little is known about the

cricket's habits and life history. This species is best known in the literature from its occurrence in greenhouses, where it has been blamed for causing occasional minor damage to plants (Vickery and Kevan 1983). Although its feeding preferences are largely unknown, D. asynamora appears

like most Rhaphidophoridae to be an omnivorous scavenger, and has been reported foraging on

Ceuthophilus spp. are only somewhat better known than those of D. asynamora. Species of 
242 Ceuthophilus (including taxa sometimes found in houses) have been observed scavenging

243 opportunistically on a range of food sources including other insects, fungi, and fallen fruit

244 (Taylor, Krejca, and Denight 2005). Examination of several cave-associated Ceuthophilus species

245 (Northup 1988) revealed a diverse diet that included mammalian carcasses, feces, other insects

246 (including cannibalized Ceuthophilus individuals), and human food waste. Like D. asynamora,

247 some species of Ceuthophilus appear to be occasional predators of other insects (Taylor, Krejca,

248 and Denight 2005, Vickery and Kevan 1983). Although we know little about the life history of

249 D. asynamora or Ceuthophilus in houses, D. asynamora is reported to breed year-round in heated

250 greenhouses. Breeding in D. asynamora is thought to occur only in the dark, and eggs are

251 typically laid in the soil (Vickery and Kevan 1983).

252 Although Ceuthophilus and Diestrammena both appear to be fairly generalized omnivores, we

253 can infer little about the extent to which these insects' habits and life histories are comparable

254 (and hence might lead to direct or indirect competition) in houses. Differences in the natural

255 history of the two taxa potentially could affect the extent to which these crickets would be

256 perceived by our citizen scientist contributors. For example, if the principal species of

257 Ceuthophilus in houses were found to be more reclusive than D. asynamora, this could in part

258 explain the larger number of $D$. asynamora reports by our contributors. However, the results of

259 our pitfall experiment suggest that for at least some areas the perception of greater numbers of $D$.

260 asynamora than Ceuthophilus associated with houses is real, especially considering that

261 numerous individuals of various Ceuthophilus species (including those sometimes found in

262 houses) have been commonly recovered from molasses-baited pitfall traps in other studies not

263 near houses (Blatchley 1920; Hubbell 1936; Taylor, Krejca, and Denight 2005). Although we

264 might expect larger insects to be noticed more readily by citizen scientists, the principal species 
265 of Ceuthophilus occurring in houses are in fact slightly larger on average than D. asynamora

266 (Blatchley 1920). Hence, the more numerous reports of D. asynamora relative to Ceuthophilus do

267 not appear to have been biased by body size. Nonetheless, we recommend future study to

268 understand the relative life histories of these species, their interactions with each other and other

269 house-dwelling arthropods, and the ways in which they use our houses as habitat.

270 The appearance of a second introduced species, Diestrammena japanica, as an exotic in the

271 United States has never before been recorded in the literature, although its presence has been

272 reported anecdotally in some northeastern states concordant with those found in our study (see

273 www.bugguide.net). Some confusion arises in the erroneous early use of the name D. japanica as

274 a synonym for D. asynamora (Blatchley 1920), a misapplication subsequently clarified by Rehn

275 (1944). Aside from D. asynamora only one other species of Diestrammena has been reported in

276 the literature from the United States. This second species, reported by Morse (1904) as $D$.

277 unicolor, is known in the United States from only a single specimen collected in a greenhouse in

278 Chicago. This specimen, described as being uniformly piceous in color (Blatchley 1920), is

279 clearly distinct from our records of $D$. japanica, despite any potential nomenclatural

280 incongruities.

281 In our study, the presence of two species of Diestrammena in our samples is confirmed by the

282 widely divergent number of tibial spines between D. asynamora and D. japanica (ca. 60 and 30

283 respectively; Sugimoto and Ichikawa 2003), a character clearly visible in many of the

284 photographs submitted. Although our identification of the species D. asynamora was confirmed

285 on the basis of at least 170 specimens as well as by photographs, our records for D. japanica

286 were based on photographs only, and we must therefore allow for some uncertainty as to the

287 identity of the second species as the true D. japanica. Photographs of the second Diestrammena 
288

289

290

291

292

293

294

295

296

297

298

299

300

301

302

303

304

305

306

307

308

309

310

species were identified as $D$. japanica based on a combination of outwardly visible characters

such as tibial spur length, tibial spine number, pronotal luster, and coloration (Sugimoto and

Ichikawa 2003). In addition, the distinctive pronotal pattern of D. japanica (Sugimoto and

Ichikawa 2003) was an exact match for our specimens. Although we offer clear evidence for the

presence of two introduced species of Diestrammena in the United States, we recommend future

study of museum specimens and examination of male genitalia (ideally in comparison with type

material) to confirm the second species as D. japanica.

Our collections of camel crickets from pitfall traps in urban yards revealed that D. asynamora is not restricted to house environments, but is also a common presence in adjacent yards. Whether these same individuals present in yards are also moving in and out of houses is unclear. The fact that these crickets were significantly more abundant in traps placed within a meter of the house (Fig. 6) suggests that D. asynamora may be closely associated with human dwellings even when found in outdoor habitats. However, as we did not account for potential variability in local habitats within a transect (e.g., traps placed $1 \mathrm{~m}$ from houses could have been more proximate to bushes compared to further traps), such variation may have biased our transect results.

Surprisingly, no native camel crickets were recovered from any of these traps. Although behavioral differences (e.g., in activity level) between cricket species could potentially cause one species to appear more readily in pitfalls, pitfall traps baited with molasses have repeatedly been shown in other work to be highly profitable for sampling Ceuthophilus spp. (Blatchley 1920;

Hubbell 1936; Taylor, Krejca, and Denight 2005). This suggests that in some localities $D$. asynamora may be the dominant camel cricket not only in houses but also in urban yards. However, it is yet unclear whether D. asynamora has also invaded wilder habitats with less human disturbance, or if in North America the species persists exclusively in habitats associated 
311 with anthropogenic structures. The extent to which D. asynamora has actually displaced or is

312 actively competing with native populations of Ceuthophilus (a genus that includes a number of

313 rare or sensitive species) is also unknown, and further study is needed to determine whether this

314 new invader poses an ecological threat, or is merely a harmless visitor in our houses and yards.

315 ACKNOWLEDGEMENTS

316 We would like to thank Lauren Nichols for mapping assistance, and David Ferguson and Piotr

317 Naskrecki for initial advice on Diestrammena identification. Piotr Naskrecki, Terry Wheeler, and

318 two anonymous reviewers provided helpful comments on the manuscript. We are also grateful to

319 Lea Shell for help with public outreach and data management, and to Neil McCoy for technical

320 and design assistance with the project website and associated data collection. Andrew Blanchard

321 and Kathy Kinney kindly allowed us use of their photographs for Figure 4a and b, respectively.

322 We extend our warmest thanks to the many citizen scientists and survey participants who aided

323 this project, without whose help this study would not have been possible.

324 REFERENCES

325 Allegrucci G, Minasi MG, and Sbordoni V. 1997. Patterns of gene flow and genetic structure in

326 cave-dwelling crickets of the Tuscan endemic, Dolichopoda schiavazzii (Orthoptera,

327 Rhaphidophoridae). Heredity 78:665-673.

328 Arnett RH. 2000. American Insects: A Handbook of the Insects of America North of Mexico:

$329 \quad$ CRC Press.

330 Blatchley WS. 1920. Orthoptera of northeastern America, with especial reference to the faunas

331 of Indiana and Florida. Indianapolis, IN: The Nature Publishing Company.

332 Bonney R, Cooper CB, Dickenson J, Kelling S, Phillips T, Rosenberg KV, and Shirk J. 2009.

333 Citizen science: A developing tool for expanding science knowledge and scientific

$334 \quad$ literacy. Bioscience 59:977-984.

335 Bue IG and Munro JA. 1939. Notes on the biology and control of the greenhouse stone cricket.

336 Journal of Economic Entomology 32:468. 
337 Chopard L. 1928. Sur une gravure d'insecte de l'epoque magdalénienne. Comptes Rendus de la

338 Societé de Biogeographie 5:64-67.

339 ESRI 2006 ArcMap. Redlands, CA: ESRI.

340 Hubbell TH. 1936. A monographic revision of the genus Ceuthophilus (Orthoptera,

341 Gryllacrididae, Rhapidophorinae): University of Florida Publication.

342 Lavoie KH, Helf KL, and Poulson TL. 2007. The biology and ecology of North American cave

343

344

345

346

347

348

349

350

351

352

353

354

355

356

357

358

359

360

361

362

363

364

365 crickets. Journal of Cave and Karst Studies 69:114-134.

Morse AP 1904. Diestrammena unicolor in North America. Psyche 11:80-80.

Northup, D. E. 1988. Community structure of the arthropods of Carlsbad Cavern emphasizing Rhaphidophoridae of the genus Ceuthophilus. M.Sc. Thesis, University of New Mexico.

$53 \mathrm{p}$.

Nowak DJ, and Walton JT. 2005. Projected urban growth (2000-2050) and its estimated impact

on the US forest resource. Journal of Forestry 103:383-389.

Rehn JAG. 1944. The rhaphidophorid Tachycines asynamorus Adelung in America (Orthoptera,

Gryllacrididae, Rhaphidophorinae). Entomological News 55:36-39.

U.S Census Bureau. 2012. Annual estimates of housing units for United States and States: April 1

2010 to July 12011 . HU-EST2011-01.

Stein BA, Kutner LS, and Adams JS. 2000. Precious heritage: the status of biodiversity in the

United States. Oxford, United Kingdom: Oxford University Press.

Sugimoto M, and Ichikawa A. 2003. Review of Rhaphidophoridae (excluding Protrogrophilinae)

(Orthoptera) of Japan. Tettigonia 5:1-48.

Taylor SJ, Krejca JK, and Denight ML. 2005. Foraging range and habitat use of Ceuthophilus

secretus (Orthoptera: Rhaphidophoridae), a key trogloxene in central Texas cave

communities. American Midland Naturalist 154:97-114.

United Nations. 2012. World urbanization prospects: The 2011 revision. Department of

Economic and Social Affairs, Population Division. Available online at:

http://esa.un.org/unup/ Accessed 12.05.14.

Vickery VR, and Kevan DK. 1967. Records of the orthopteroid insects of Ontario. Proceedings

of the Entomological Society of Ontario 97:13-68. 
366 Vickery VR, and Kevan DK. 1983. A monograph of the orthopteroid insects of Canada and

367 adjacent regions. Ste. Ane de Bellevue, Quebec: Lyman Entomological Museum and 368 Research Laboratory. 


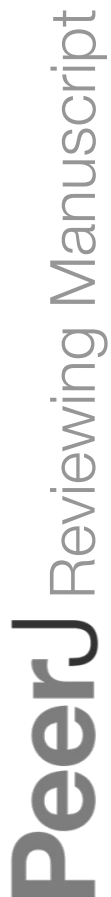

PeerJ reviewing PDF | (v2014:05:2109:1:0:ACCEPTED 21 Jul 2014) 


\section{Figure 1}

Percentage of households by state reporting the presence of camel crickets around the home

Responses to the Wild Life of Our Home survey, showing the percentage of households from each state answering 'yes' to the question 'have you seen camel crickets in or around your home?'. Numerals in each state represent the total number of responses (yes or no) for that state.

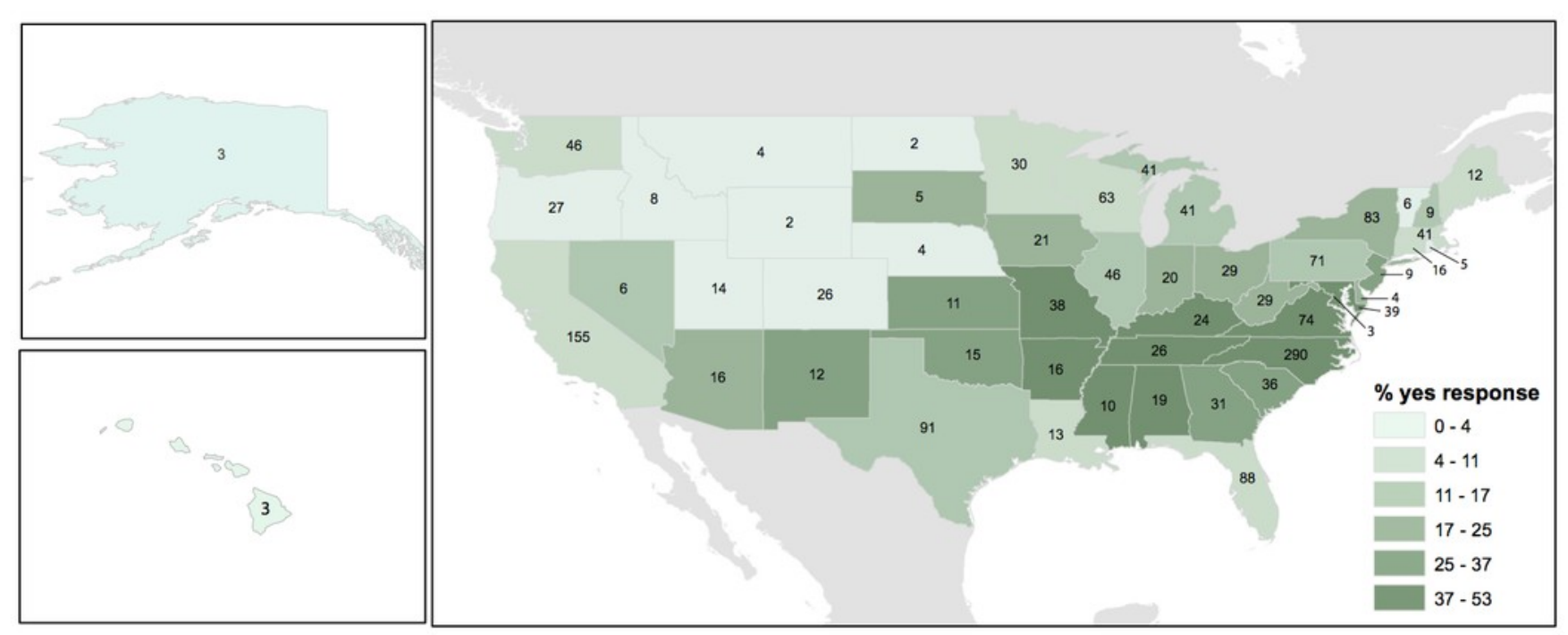




\section{Figure 2}

Survey responses showing presence or absence of camel crickets in homes

Map of combined responses to the open survey question and the Wild Life of Our Homes survey question asking citizens if they have observed camel crickets in their houses. Blue points represent positive reports of camel crickets found in homes $(N=669)$, whereas red points indicate households where camel crickets have not been knowingly observed ( $N=$ $1,598)$.

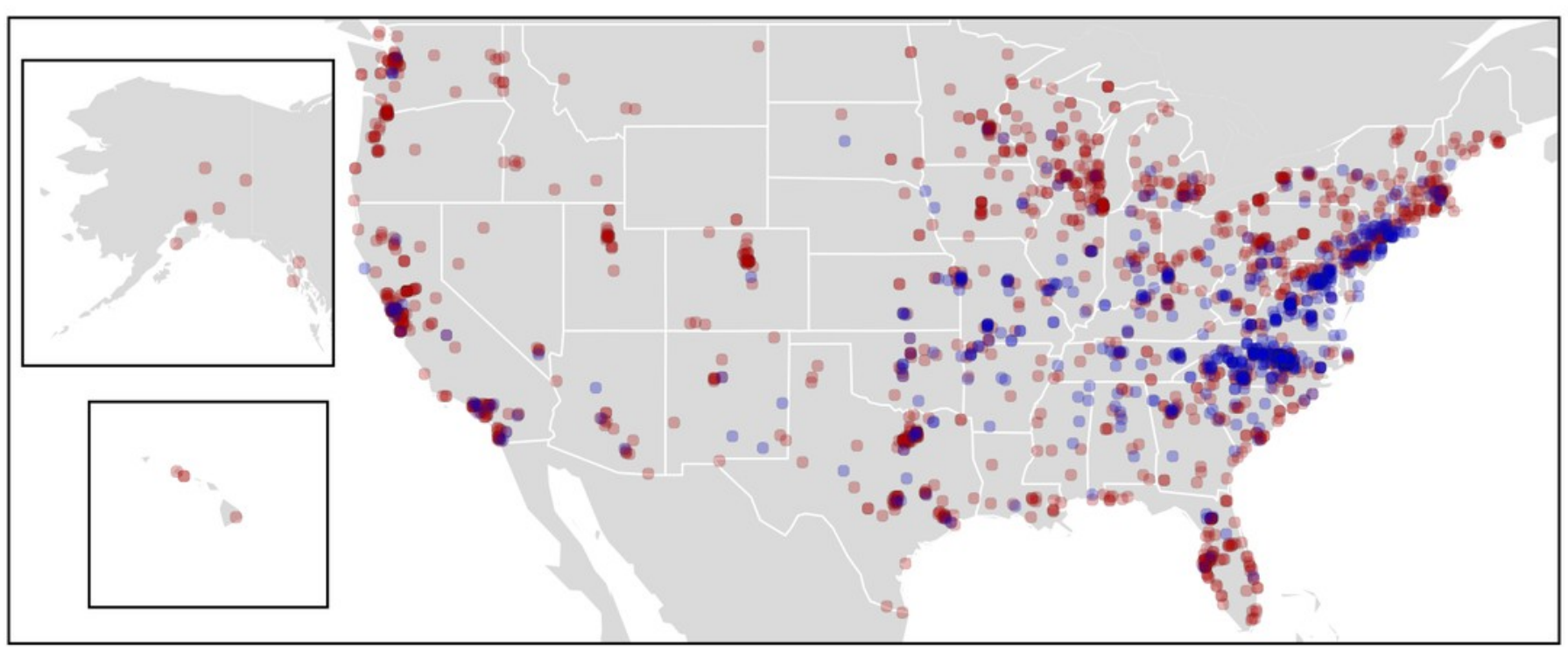




\section{Figure 3}

Distribution of Ceuthophilus and Diestrammena in homes

The distribution of native Ceuthophilus spp. (black circles; $N=20$ ) versus exotic

Diestrammena spp. camel crickets (white points; $N=143$ ) in homes, based on photographic and specimen submissions contributed by citizen scientists.

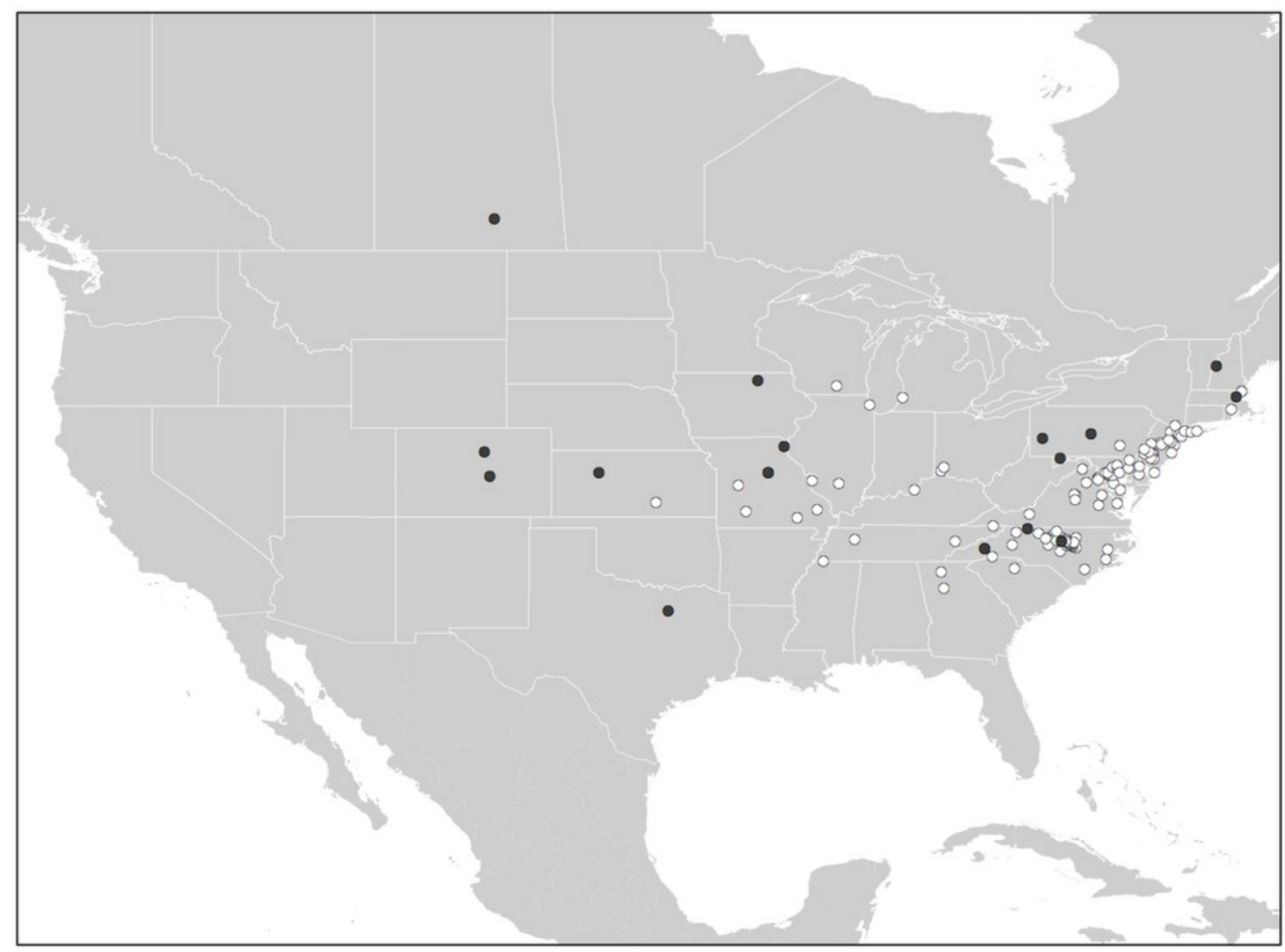




\section{Figure 4}

Images of Diestrammena asynamora and putative $D$. japanica.

Photographs of the two species of Diestrammena submitted by citizen scientists, showing (a) D. asynamora (Andrew Blanchard, Creative Commons Attribution License 2014) and (b) putative D. japanica (Kathryn Kinney, Creative Commons Attribution License 2014).

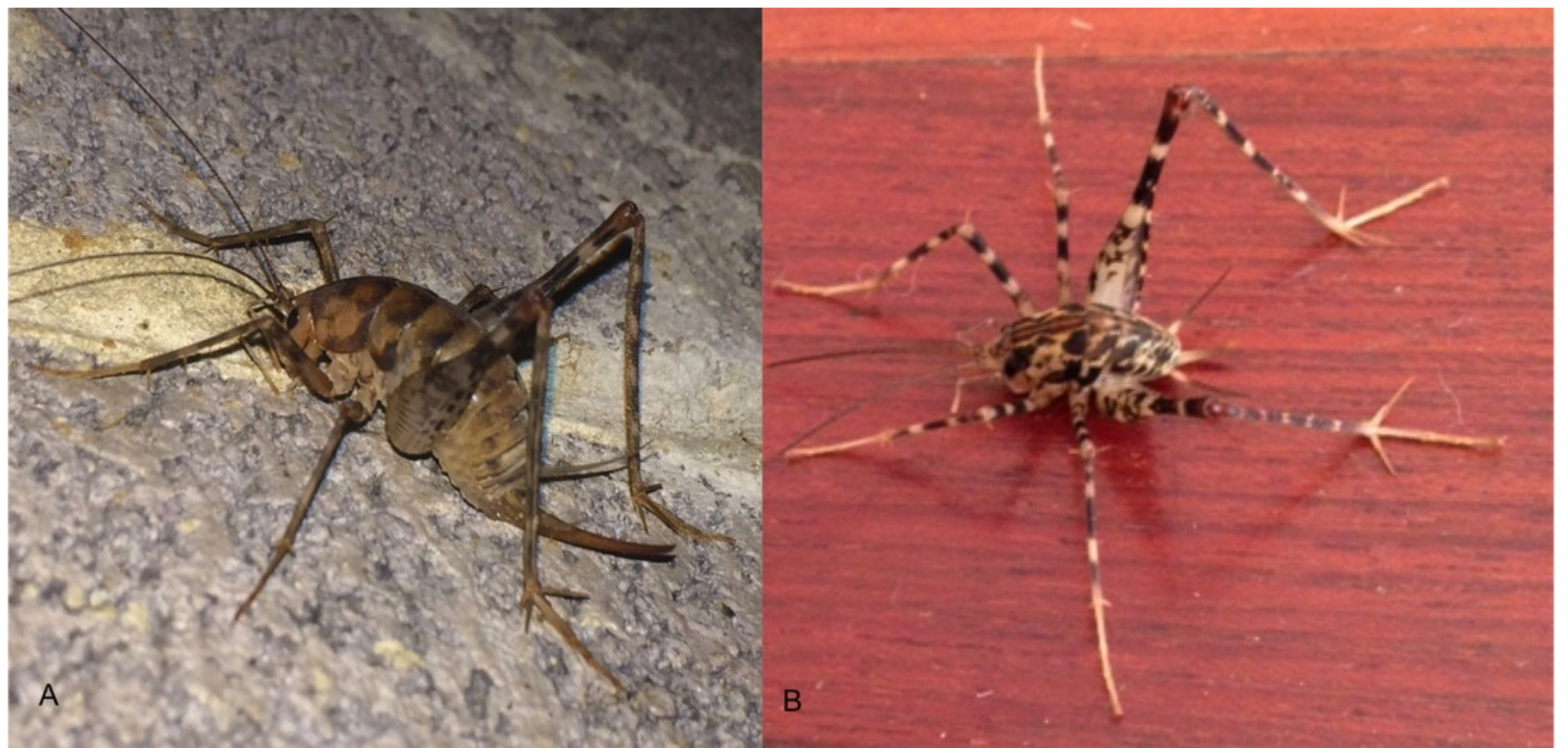




\section{Figure 5}

Distribution of Diestrammena species in American houses.

The relative distribution of the two Diestrammena species reported from houses in the United States, as indicated by photographs and/or specimens from citizen scientists. Records of $D$. asynamora $(N=101)$ are indicated in grey, $D$. japanica $(N=7)$ in white.

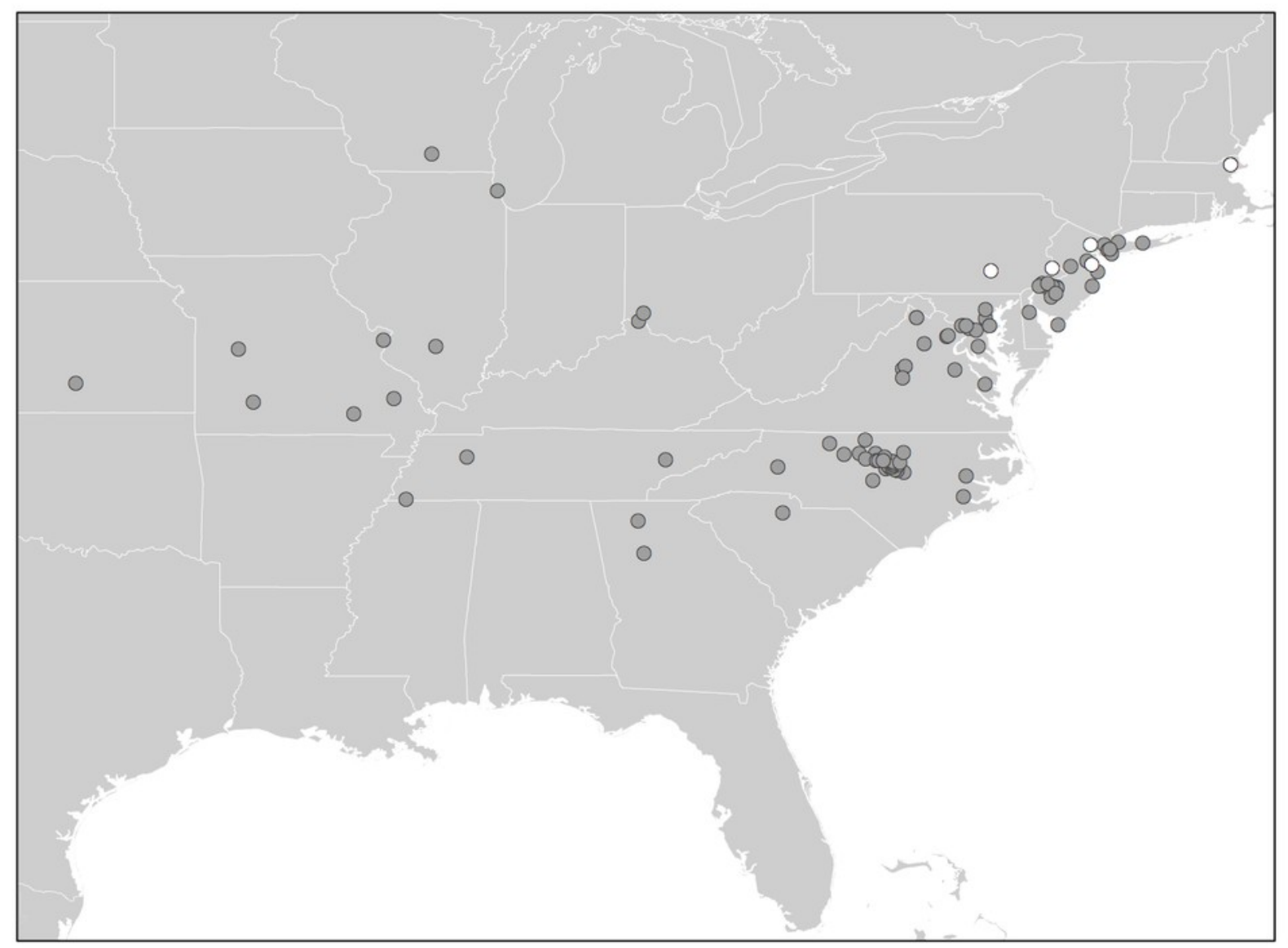




\section{Figure 6}

The number of $D$. asynamora crickets in yard traps as a function of the distance from a house.

The number of $D$. asynamora individuals recovered from a pitfall trap was negatively correlated with the distance of a trap from a house $\left(R^{2}=0.66, P=0.004\right.$ from ANCOVA, after accounting for individual yard effect). Each dot represents a single pitfall trap $(N=21$, with three traps placed in each of seven yards).

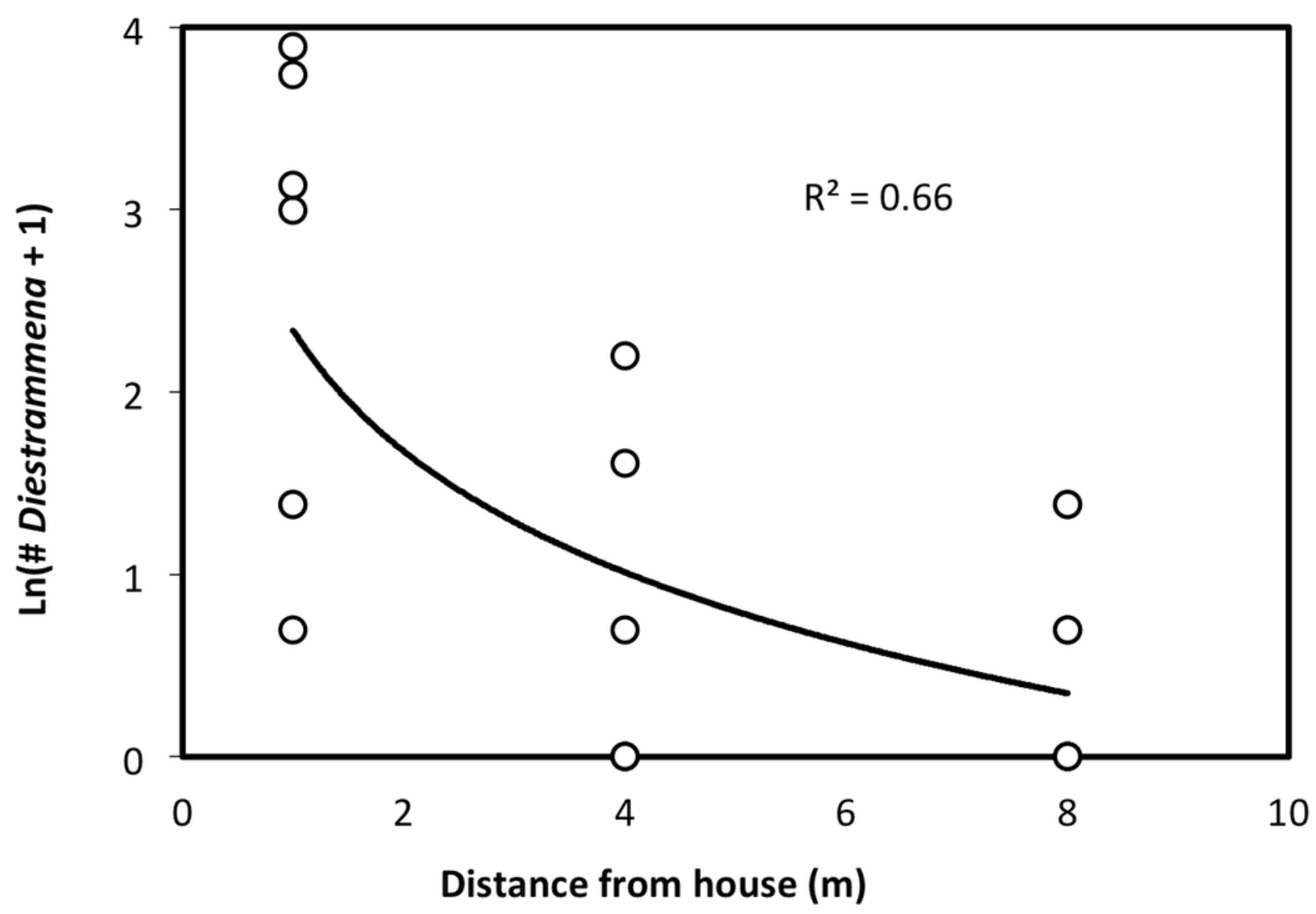




\title{
Table $\mathbf{1}_{\text {(on next page) }}$
}

Number of houses with camel crickets by state

\author{
Results of citizen-contributed photographic or specimen submissions showing the relative \\ number of households with the Asian Diestrammena versus native Ceuthophilus samples by \\ state or Canadian province. Two houses in North Carolina each contributed specimens of \\ both genera. The subset of households submitting photographs and/or specimens of \\ Diestrammena that could be determined to species are further distinguished to show the \\ relative number and distribution of records for $D$. asynamora versus putative $D$. japanica.
}




\section{\# Houses with}

\begin{tabular}{|c|c|c|c|c|c|}
\hline State or province & $\begin{array}{c}\text { Total } \\
\text { responses }\end{array}$ & $\begin{array}{l}\text { \# Houses with } \\
\text { Ceuthophilus }\end{array}$ & $\begin{array}{l}\text { \# Houses with } \\
\text { D. asynamora }\end{array}$ & $\begin{array}{c}\text { \# Houses with } \\
\text { D. japanica }\end{array}$ & $\begin{array}{c}\text { Diestrammena sp. } \\
\text { (unidentified) }\end{array}$ \\
\hline Colorado & 2 & 2 & 0 & 0 & 0 \\
\hline Delaware & 2 & 0 & 1 & 0 & 1 \\
\hline Georgia & 2 & 0 & 2 & 0 & 0 \\
\hline Iowa & 1 & 1 & 0 & 0 & 0 \\
\hline Illinois & 2 & 0 & 2 & 0 & 0 \\
\hline Kansas & 2 & 1 & 1 & 0 & 0 \\
\hline Kentucky & 1 & 0 & 0 & 0 & 1 \\
\hline Massachusetts & 3 & 1 & 0 & 2 & 0 \\
\hline Maryland & 17 & 1 & 10 & 0 & 6 \\
\hline Michigan & 1 & 0 & 0 & 0 & 1 \\
\hline Missouri & 9 & 4 & 5 & 0 & 0 \\
\hline North Carolina & 60 & 5 & 41 & 0 & 14 \\
\hline New Hampshire & 1 & 1 & 0 & 0 & 0 \\
\hline New Jersey & 16 & 0 & 12 & 2 & 2 \\
\hline New York & 9 & 0 & 7 & 0 & 2 \\
\hline Ohio & 2 & 0 & 2 & 0 & 0 \\
\hline Pennsylvania & 10 & 2 & 4 & 2 & 2 \\
\hline Saskatchewan & 1 & 1 & 0 & 0 & 0 \\
\hline South Carolina & 1 & 0 & 1 & 0 & 0 \\
\hline Tennessee & 3 & 0 & 3 & 0 & 0 \\
\hline Texas & 1 & 1 & 0 & 0 & 0 \\
\hline Virginia & 15 & 0 & 10 & 0 & 5 \\
\hline Wisconsin & 1 & 0 & 1 & 0 & 0 \\
\hline District of Columbia & 1 & 0 & 0 & 0 & 1 \\
\hline Total records & 163 & 20 & 102 & 6 & 35 \\
\hline
\end{tabular}

